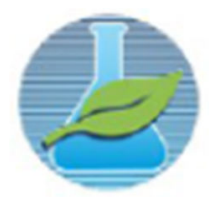

\title{
ANÁLISE POR MEIO DO MÉTODO DE ELEMENTOS FINITOS DAS TENSÕES-DEFORMAÇÕES NAS ENGRENAGENS DA CAIXA DE TRANSMISSÃO DO VEÍCULO BAJA
}

\author{
Arnaldo Alexandre Hygino de Medeiros, Geice Paula Villibor \\ Universidade Federal de Viçosa-UFV, Departamento de Engenharia Mecânica e Produção \\ Campus UFV - 36570-900 - Viçosa - MG \\ arnaldo.medeiros@ufv.br
}

\section{INTRODUÇÃO}

O veículo fora de estrada tipo baja, é monoposto e robusto e deve estar atrelado com as regras de segurança e desempenho definidas pelo Regulamento Baja SAE Brasil. Esses veículos têm que apresentar agilidade e capacidade de trabalhar em terrenos irregulares e de baixa sustentação. Durante as competições nacional e regional, o veículo projetado pelos estudantes passa por diversas provas, dentre as quais citamos o enduro e o suspension and traction. Tais provas exigem muito do sistema de transmissão do veículo, que trabalha maximizando o torque fornecido pelo motor no que o veículo necessita. Nesse caso as engrenagens que fazem parte da redução do carro são componentes chaves. Caso o dimensionamento das engrenagens não for efetuado de forma correta, pode levá-las a uma falha prematura. Tal situação ocorreu no projeto da coroa do segundo estágio da redução no carro que foi avaliado na Competição Baja SAE 2014, o que levou a sua falha bem antes do esperado, com cerca de 9 horas de uso.

\section{OBJETIVO}

O presente trabalho teve por objetivo realizar uma análise estrutural utilizando o MEF a fim de entender o motivo da falha da engrenagem do segundo estágio de redução do veículo UFVbaja de 2014, para assim projetar uma nova com parâmetros de projetos diferentes que a deixe mais resistente, evitando que esta sofra a mesma falha da antiga.

\section{METODOLOGIA}

Para alcançar esse objetivo a seguinte metodologia foi adotada: Calcular os esforços que agiram na engrenagem do segundo estágio de redução de 2014 que falhou, e através do seu desenho 3D realizar uma análise estrutural, através de simulações estáticas e de fadiga utilizando o MEF, a fim de concluir sobre o motivo de sua falha. Utilização das equações de tensão de flexão e contato da AGMA para o dimensionamento de uma nova engrenagem com algumas modificações dos fatores de projeto que os cálculos mostrarem necessárias. Realizar o desenho 3D da nova engrenagem em CAD e realizar as mesmas simulações da engrenagem de 2014 utilizando o MEF. Comparar os resultados das simulações da engrenagem de 2014 e 2015, a fim de quantificar o quanto as modificações de projeto da nova coroa foram eficazes para o aumento de sua resistência em relação à antiga, através da comparação dos seus coeficientes de segurança contra escoamento de primeiro ciclo mostrado na Eq. (1) e de fadiga (método de Gerber) mostrado na Eq. (2): 


$$
\begin{aligned}
& n=\frac{S_{y}}{\sigma_{m}+\sigma_{a}} \\
& n_{f}=\frac{1}{2}\left(\frac{S_{u t}}{\sigma_{m}}\right)^{2} \frac{\sigma_{a}}{S_{e}}\left[-1+\sqrt{\left(1+\frac{2 \sigma_{m} S_{e}}{S_{u t} \sigma_{a}}\right)^{2}}\right]
\end{aligned}
$$

\section{RESULTADOS}

$\mathrm{Na}$ análise da engrenagem de 2014 pelo MEF (Método de Elementos Finitos), de acordo com sua simulação estática a tensão alternada de von Mises $\left(\sigma_{a}=\sigma_{m}\right)$ foi $509,06 \mathrm{MPa}$ e sua deformação foi de $0,2256 \mathrm{~mm}$, o que levou a um coeficiente de segurança contra escoamento de primeiro ciclo (Eq. (1)) de 1,0165. Assim, o motivo de sua falha 20104 não foi o escoamento de primeiro ciclo, pois o coeficiente de segurança para o mesmo deu maior que um. O que era de se esperar, pois essa engrenagem apesar de ter falhado antes do previsto, ela ainda teve uma vida próxima de 9 horas. Isso mostra que sua falha possa ter sido por fadiga.

$\mathrm{Na}$ simulação de fadiga, o programa indicou que a engrenagem antiga, de acordo com o seu projeto, daria 100000 ciclos até a sua falha. Em conversa com o responsável pelo projeto antigo, o mesmo disse que ela teoricamente foi projetada para uma vida de 30 horas, porém por algum erro de projeto, a mesma suportou apenas 9 horas de uso. Essas 9 horas de funcionamento, considerando a rotação máxima fornecida pelo motor $(3800 \mathrm{rpm})$ dividida pela relação global do carro antigo $(24,5)$ nos dá a rotação que chega na engrenagem $(155,1 \mathrm{rpm})$, a qual daria quase 84000 ciclos até a falha. Podemos ver que a rotação teórica calculada é próxima ao que o Ansys ${ }^{\circledR}$ indica na simulação, tendo um erro de $16 \%$.

O coeficiente de segurança que resguarda contra fadiga proposto por Gerber (Eq. (2)) foi de 0,83. Como esse valor é menor que 1 e encontra-se abaixo do coeficiente de segurança que resguarda contra escoamento de primeiro ciclo, concluiu-se que segundo a simulação pelo MEF a falha da engrenagem de 2014 foi por fadiga, após 100000 ciclos. Que foi próximo do que realmente ocorreu, como foi descrito acima.

Após concluído o motivo da falha da engrenagem de 2014, uma nova engrenagem foi projetada de acordo com Budybas (2011) e Norton (2000). Os cálculos mostraram que a largura de face, espessura de borda e espessura do raiado teriam que ser maiores em relação à de 2014, para que ela tivesse a resistência necessária para resistir aos esforços do engrenamento. A Tab. 1 mostra as modificações feitas na nova engrenagem em relação à de 2014:

Tabela 1: Comparação dos valores dos parâmetros modificados entre a engrenagem de 2014 e 2015.

\begin{tabular}{|l|l|}
\hline Engrenagem 2015 (nova) & Engrenagem 2014 (antiga) \\
\hline Espessura de borda:5 $\mathrm{mm}$ & Espessura de borda:3 $\mathrm{mm}$ \\
\hline Largura de face: $24 \mathrm{~mm}$ & Largura de face:20 $\mathrm{mm}$ \\
\hline Espessura da raiação: $19 \mathrm{~mm}$ & Espessura do raiado: $14 \mathrm{~mm}$ \\
\hline
\end{tabular}

$\mathrm{Na}$ análise da engrenagem nova pelo $\mathrm{MEF}$, o novo dimensionamento com as modificações de projeto como aumento da largura de face, espessura de borda e do raiado da nova engrenagem foi de suma importância para o ganho de resistência. A deformação sofrida pela engrenagem atual é cerca de $68 \%$ menor que a sofrida pela engrenagem antiga e a tensão alternada atuante na engrenagem nova foi quase $26 \%$ menor que a atuante na antiga.

De acordo com a Eq. (1) onde $\left(\sigma_{m}=\sigma_{a}=394,03 \mathrm{MPa}\right)$ seu coeficiente de segurança contra escoamento de primeiro ciclo é de 1,313. Como pode-se ver, ele se encontra acima de 1 com uma considerável folga (em comparação com a engrenagem antiga) e nossa engrenagem nova suportará as forças do engrenamento e não falhará por escoamento de primeiro ciclo. 
O próximo passo então foi analisar a sua vida em número de ciclos na simulação de fadiga para ver se o número de ciclos que o programa nos mostra se aproximaria do número de ciclos teóricos previstos no seu projeto de 30 horas.

O programa nos indicou que a engrenagem nova, de acordo com o seu novo projeto, dará 300000 ciclos até a sua falha. A mesma foi projetada para 30 horas de vida. Considerando a rotação máxima fornecida pelo motor $(3800 \mathrm{rpm})$ dividida pela nova relação global do carro $(22,5)$ nos dá a rotação que chega na engrenagem $(168,8 \mathrm{rpm})$, a qual dará teóricos 303000 ciclos até a falha. Podemos ver que a rotação teórica calculada é bem próxima ao que o Ansys ${ }^{\circledR}$ indica na simulação, tendo um erro de $1 \%$.

Novamente utilizando a Eq. (2), chegou-se a um coeficiente de segurança que resguarda contra fadiga de 1,071. Como esse valor é menor que o de coeficiente de segurança de escoamento de primeiro ciclo que foi de 1,313, conclui-se que a falha de nossa nova engrenagem ficará resguardada por fadiga, após 300000 ciclos que dá a ela 30 horas de vida, que está de acordo com o que foi projetada.

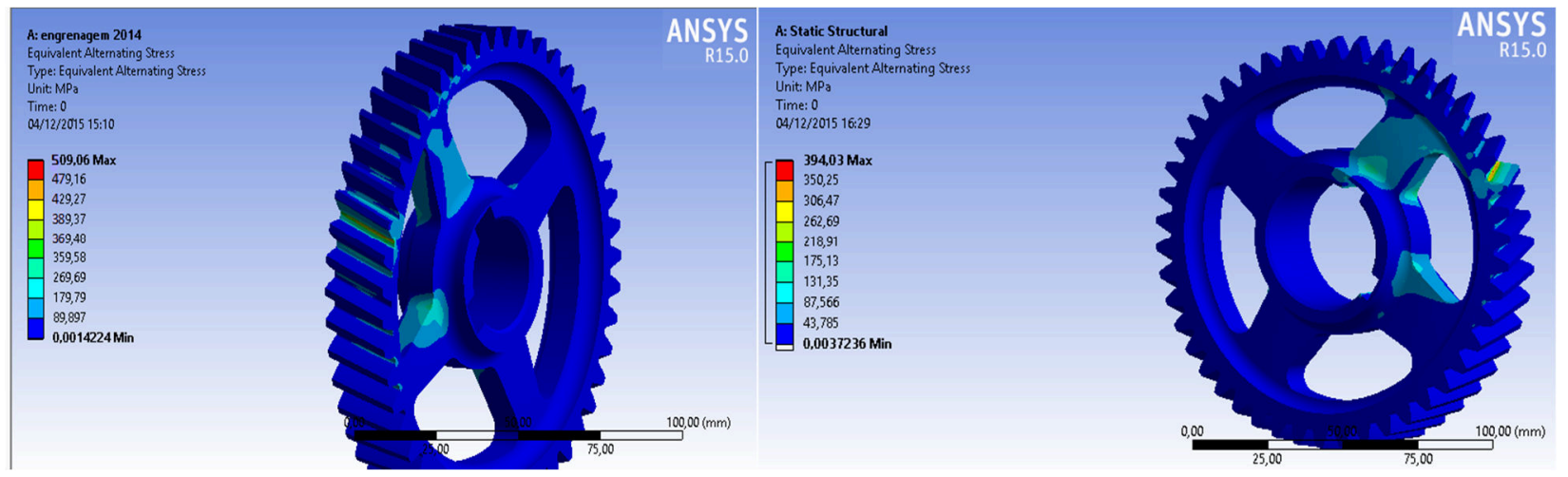

Figura 1 - Simulação estática da engrenagem de 2014 à esquerda e 2015 à direita

\section{CONCLUSÃO}

Desse modo, foi possível afirmar que as modificações de projeto, como aumento da espessura de borda, largura de face e do raiado foram essenciais para o ganho de resistência da nova engrenagem em relação à de 2014, o que deu a ela uma vida maior nas simulações que estão de acordo com a requerida no nosso projeto.

\section{REFERENCIAS}

NISBETT, J. K.; BUDYNAS, R. G. "Elementos de Máquinas de Shigley". 8. ed. São Paulo: McGraw Hill. 2011.

Norton, L. R. "Projeto de Máquinas, uma abordagem integrada" Ed. Artmed S. A., São Paulo, 2000. 